American Journal of Environmental Sciences 5 (3): 230-237, 2009

ISSN 1553-345X

(C) 2009 Science Publications

\title{
The Effect of Air Pollution on Ozone Layer Thickness in Troposphere over the State of Kuwait
}

\author{
${ }^{1}$ H.O. Al Jeran and ${ }^{2}$ A.R. Khan \\ ${ }^{1}$ Department of Applied Science, College of Technological Studied, \\ P.O. Box 14068, 72851 Faiha, Kuwait \\ ${ }^{2}$ Department of Environmental Technology and Management, \\ College for Women, Kuwait University, P.O. Box 5696, 131060 Safat, Kuwait
}

\begin{abstract}
Troposphere ozone layer acts as a shield against all ultraviolet radiation approaching the planet Earth through absorption. It was noticed in mid 80s that ozone layer has thinned on the poles of the planet due to release of man-made substances commonly known as Ozone Depleting Substances, (ODS) into its atmosphere. The consequences of this change are adverse as the harmful radiations reach to the surface of the earth, strongly influencing the crops yield and vegetation. These radiations are major cause of skin cancer that has long exposure to Ultra Violet (UV) radiation. United States environmental protection agency and European community have imposed strict regulations to curb the emission of ODS and phase out schedules for the manufacture and use of ODS that was specified by Montreal protocol in 1987. Problem statement: This research deled with data analysis of ozone layer thickness obtained from Abu-Dhabi station and detailed measurement of air pollution levels in Kuwait. Approach: The ozone layer thickness in stratosphere had been correlated with the measured pollution levels in the State of Kuwait. The influence of import of ozone depletion substances for the last decade had been evaluated. Other factor that strongly affects the ozone layer thickness in stratosphere is local pollution levels of primary pollutants such as total hydrocarbon compounds and nitrogen oxides. Results: The dependency of ozone layer thickness on ambient pollutant levels presented in detail reflecting negative relation of both non-methane hydrocarbon and nitrogen oxide concentrations in ambient air. Conclusion: Ozone layer thickness in stratosphere had been measured for five years (1999-2004) reflecting minimum thickness in the month of December and maximum in the month of June. The ozone thickness related to the ground level concentration of non-methane hydrocarbon and can be used as an indicator of the health of ozone layer thickness in the stratosphere.
\end{abstract}

Key words: Ozone depleting substances, ultraviolet radiation, stratosphere, hydrocarbon compounds, nitrogen oxides

\section{INTRODUCTION}

Ozone Depleting Substances (ODS): In the stratosphere level above $30-35 \mathrm{~km}$, the solar cycle effects the ozone layer depends of the reactions:

$\mathrm{O}+\mathrm{O}_{3} \rightarrow \mathrm{O}_{2}+\mathrm{O}_{2} ; \mathrm{O}_{2}+\mathrm{O}+\mathrm{M} \rightarrow \mathrm{O}_{3}+\mathrm{M}$

The Chapman-loss mechanism above contributes to only $25 \%$ of total ozone loss at these altitudes depending on several catalytic radicals like $\mathrm{OH}, \mathrm{NOx}^{[1]}$. A total trend of approximately -20 Dobson unit (DU) is simulated, which mainly results from CFC emissions ${ }^{[2]}$. A part $(15 \%)$ of this decrease can be attributed to a moistening of the stratosphere caused by troposphere warming $^{[3]}$.
Since the ozone hole is caused by ozone destruction by CFCs, the recovery will depend upon the decreases in CFC levels. These levels do not change overnight, nor in a few days or months. The process is very slow, involving several years. Hence, an abrupt increase of ozone level could not be attributed to CFC level changes. Since destruction by CFCs is not the only cause of ozone depletion and large dynamical upheavals can occur (even the destruction mechanism is highly sensitive to the ambient temperature), a recovery becomes a complicated affair. In a time when environmental concerns and strategies to address them increasingly transcend borders, the MF (multilateral fund) provides a working example of how developed and developing countries can cooperate to solve a vital

Corresponding Author: H.O. Al Jeran, Department of Applied Science, College of Technological Studied, P.O. Box 14068, 72851 Faiha, Kuwait 
global environmental problem while simultaneously promoting economic development ${ }^{[4]}$.

\section{MATERIALS AND METHODS}

\section{Chlorofluorocarbon (CFC) compounds:}

Chlorofluoro-carbons are a class of volatile organic compounds that have been used as refrigerants, aerosol propellants, foam blowing agents and as solvents in the electronic industry. They are chemically very uncreative and hence safe to work with. In fact, they are so inert that the natural reagents that remove most atmospheric pollutants do not react meteorological phenomenon that occurs usually in the with them, so after many years they drift up to the stratosphere where short wave UV light dissociates. In particular the source of the halogen atoms is still unknown ${ }^{[5-7]}$. The halogen compounds could play an important role not only in the troposphere $\mathrm{O}_{3}$ budget in Polar regions, but also in the oxidation Of Non-Methane Hydro Carbons (NMHCs) and Gaseous Elemental Mercury $(\mathrm{GEM})^{[8]}$. The most important CFC's for ozone depletion are: Trichlorofluoromethane, $\mathrm{CFCl}_{3}$ (usually called $\mathrm{CFC}-11$ or $\mathrm{R}-11)$; Dichlorodifluoromethane, $\mathrm{CF}_{2} \mathrm{Cl}_{2}$ (CFC-12 or R12) and 1, 2 Tri-chlorotrifluoro-ethane, $\mathrm{CF}_{2} \mathrm{ClCFCl}_{2}$ (CFC-113 or R-113). "R" stands for "refrigerant". One occasionally sees CFC-12 referred to as "F-12" and so forth; the "F" stands for "Freon", DuPont's trade name for these compounds, ozone depletion, "CFC" is used to describe a somewhat broader class of chlorinecontaining organic compounds that have similar properties - uncreative in the troposphere, but readily photolyzed in the stratosphere. These include Hydro Chloro-fluorocarbons such as $\mathrm{CHClF}_{2}$ (HCFC-22, R22); Carbon Tetrachloride (tetrachloro-methane), $\mathrm{CCl}_{4}$ Methyl Chloroform (1, 1,1 dichloromethane), $\mathrm{CH}_{3} \mathrm{CCl}_{3}$ (R-140a) and Methyl Chloride (chloromethane), $\mathrm{CH}_{3} \mathrm{Cl}$. The achievements of the Montreal Protocol are deeper and more far-ranging than the story told by the data alone, impressive as that is. Average annual report of 2003/2004 concerning ODP consumptions shows, significant uses include CFCs, HCFCs, methyl bromide and carbon tetrachloride, Out of these HCFCs and $\mathrm{CH}_{3} \mathrm{Br}$ are still fairly widely used in developed (nonArticle 5 (1)) countries. CFCs were scheduled for $85 \%$ phase-out in Article 5(1) countries in 2007 and complete phase out by 2010; in these countries, 2004 levels of consumption were still $40 \%$ above the baseline. Carbon tetrachloride was scheduled for $85 \%$ reduction from the 1998-2000 baselines in 2005 and is to be eliminated by 2010 , though there is a provision for exemptions totaling less than $15 \%$ of baseline extending indefinitely ${ }^{[4]}$. Studying the weight of substances which are imported to the Kuwait yearly (subheading 2903-2903.19-2903.45-903.49) with the weight of halogenated derivatives of hydrocarbons controlled by virtue of the Amendment to the Montreal Protocol on substances that deplete the ozone layer that imported Kuwait yearly (subheading 2903 are shown in Table 1 and 2 respective, whereas the graphical representation is shown in Fig. 1.

Where as total non-QPS $\mathrm{CH}_{3} \mathrm{Br}$ consumption actually increased from 2003-2004 that the reductions in use have not been as rapid in this sector as in others. In the United States, which has received the largest exemptions, 2004 consumption more than doubled 2002 consumption and 2005-2008 CUEs, while declining from year to year, are for amounts greater than 2004 consumption $^{[4]}$.

Table 1: The weight of substances imported Kuwait yearly by virtue of the amendment to the Montreal Protocol that deplete the ozone layer

\begin{tabular}{ll}
\hline Years & Halogenated hydrocarbons (Tons) \\
\hline 2000 & 3666 \\
2001 & 4568 \\
2002 & 3472 \\
2003 & 4205 \\
2004 & 4230 \\
2005 & 4965 \\
2006 & 5705 \\
Nov 2007 & 4053 \\
\hline
\end{tabular}

Table 2: The weight of substances controlled by virtue of the Amendments to the Montreal. Protocol on substances that were Imported in Kuwait yearly (Subheading 2903.192903.45-2903.49)

\begin{tabular}{ll}
\hline Years & Halogenated hydrocarbons (Tons) \\
\hline 2003 & 821 \\
2004 & 1970 \\
2005 & 2354 \\
2006 & 2412 \\
Nov 2007 & 1269 \\
\hline
\end{tabular}

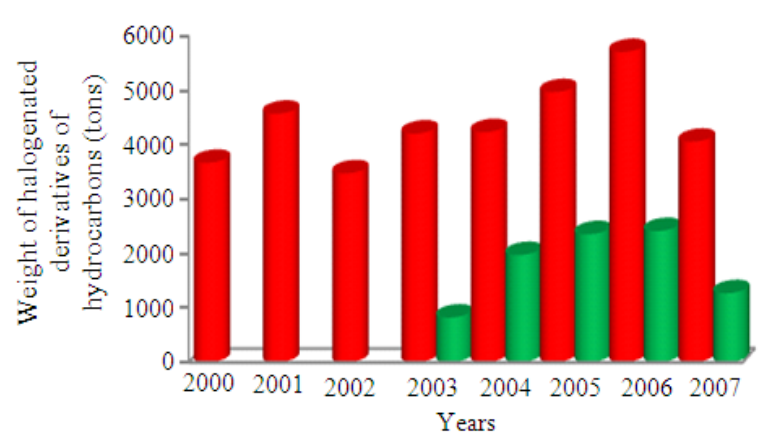

Fig. 1: Weight of substances Depleting Ozone layer Imported Kuwait (Tons) Vs Years 


\section{RESULTS AND DISCUSSION}

The influence of Total Hydrocarbon compound (THC) on troposphere ozone layer: The organic material found in the troposphere is often associated with inorganic aerosols such as dust particles. Sources of organics in the atmosphere have biogenic and anthropogenic origins in both marine and continental environments. In marine environments, biological processes are responsible for the emission of organic matter, as unsaturated fatty acids present in lipid compounds are released through ocean sprays and carried into the troposphere. Over land, in non-urban areas, aerosols can contain variety of carbon compounds including aliphatic hydrocarbons, alcohols and aromatics.

In urban areas, organic matter is mainly released directly into the troposphere through such anthropogenic means as cooking meat, automobile exhaust, leaf abrasions, wood smoke and natural gas combustion ${ }^{[6]}$. Several studies probing the interaction of ozone on the surface-bound organic material indicate that the sites of unsaturation in such fatty acid compounds act as reactive centers for ozone, producing formaldehyde in the gas phase, among other gas-phase and surface-bound products $^{[9]}$. To study the effects of THC on ozone layer, five different stations (Al-Mansouriah, Al-Rabia, AlRiga, Al-Jahra and Om-Al-Heaman) were taken, which covers almost maximum Kuwait. Out of them only on three stations (Al Mansouriah, Al Rabia and Al Riqa) the data of measured yearly mean concentration of THC were available, which showed on Fig. 2. The higher concentration was on Al-Mansouriah, because it is near the capital, due to a lot of traffic it is always-busy and big population is living around this area.

Although the chemical mechanism of the halogenatom-induced $\mathrm{O}_{3}$ depletion in the polar boundary layer subsequently has been investigated during several intense old campaigns, it is not yet fully understood.

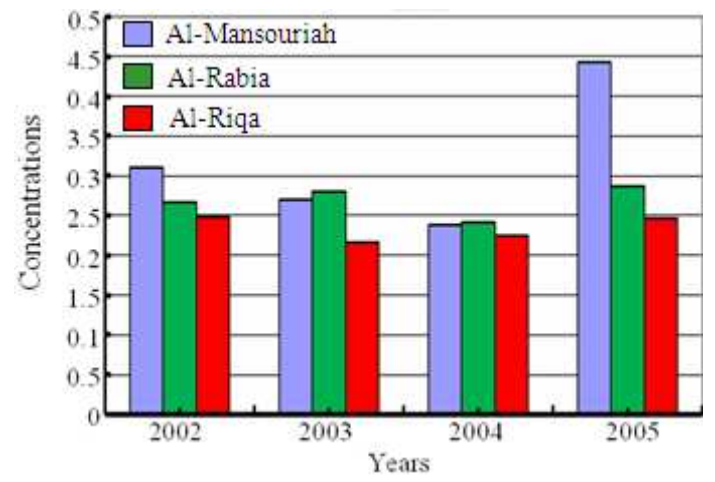

Fig. 2: Yearly mean concentration of THC by locations
In Kuwait, most of the time non-methane hydrocarbon concentrations in the ambient air are above the Kuwait Environment Public Authority (KEPA) limits depicting oil related activities. This high organic load and NOx concentrations in the presence of solar radiation, facilitates generation of ozone and carbonyls (aldehydes) that can enter into indoor air through air exchange and accumulate. As Ozone layer thickness is a function of Total hydrocarbons so to find out the relation between minimum and maximum yearly Ozone.

Thickness with the variation of THC, for the period of five years (1999-2003) at Al-Riga station, Number of graphical representations is shown in Fig. 3. So the minimum ozone thickness was recorded in the year of 1999 for variation of THC. This result supports for the year of 1999 that for every ppm of THC the minimum yearly ozone thickness is reducing by a factor of 9 , whereas for the same month the maximum yearly ozone thickness has decreased more frequently with a factor of 24.1 .

For the next year, in 2000 the minimum yearly ozone thickness is not as much reducing as in case of maximum yearly ozone thickness. Mean for the year 2000 maximum yearly ozone thickness reduces from 310-250 DU as there is little change in the concentration of THC increases from 4-5.5 ppm.

For the year of 2001 it is showing a strong positive correlation between $\mathrm{O}_{3}$ depletion events and the THC, as the rate of change of ozone thickness is more drastic as compare to previous years and found there is inversely proportional relationship between ozone thickness and THC. In this year the change in the minimum yearly ozone thickness is high as compare to maximum.

For the year of 2002 there is not any obvious trend for the minimum yearly ozone thickness value and THC, where as for maximum yearly ozone thickness the change is obvious and relation is inversely proportional.

Finally for the year of 2003 the relation between ozone layer thickness and THC are not very clear.

It is hence ofs interest to examine how strongly the results change if depletion of ozone thickness is related to THC. This supports the idea that the depletion of $\mathrm{O}_{3}$ is associated with concentrations of THC in the troposphere.

Considering the seasonal variation such as summer, spring, autumn and winter that come in Arabian gulf area in January, March, May and August respectively. As shown Fig. 4, there are inverse proportional between Ozone thickness and THC but the slope is changing sharply on spring season then summer. A strong positive correlation between springtime $\mathrm{O}_{3}$ depletion events and the THC was observed. 
Am. J. Environ. Sci., 5 (3): 230-237, 2009
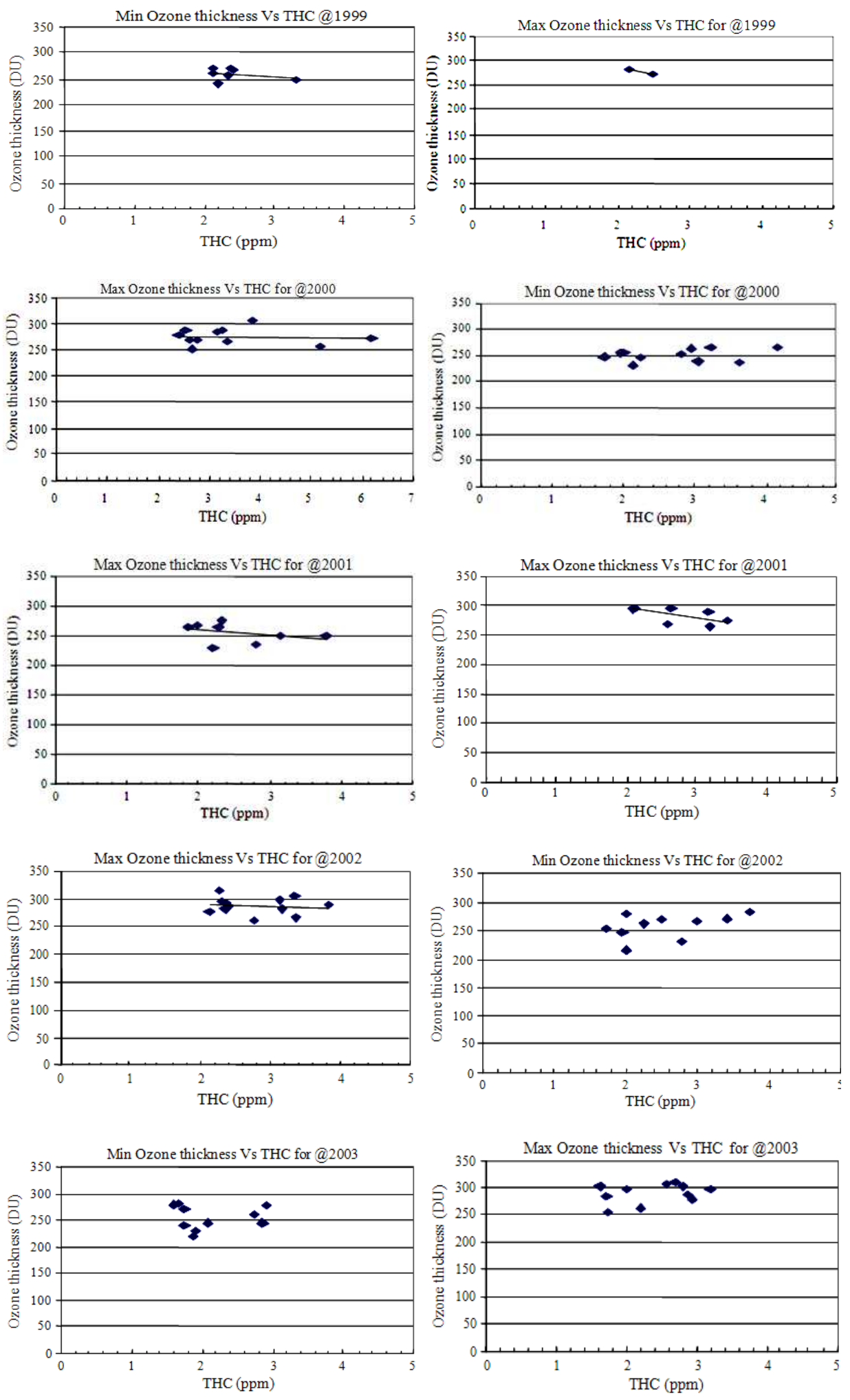

Fig. 3: Minimum and maximum yearly ozone thickness VS .THC on Al-Riga station 
Am. J. Environ. Sci., 5 (3): 230-237, 2009
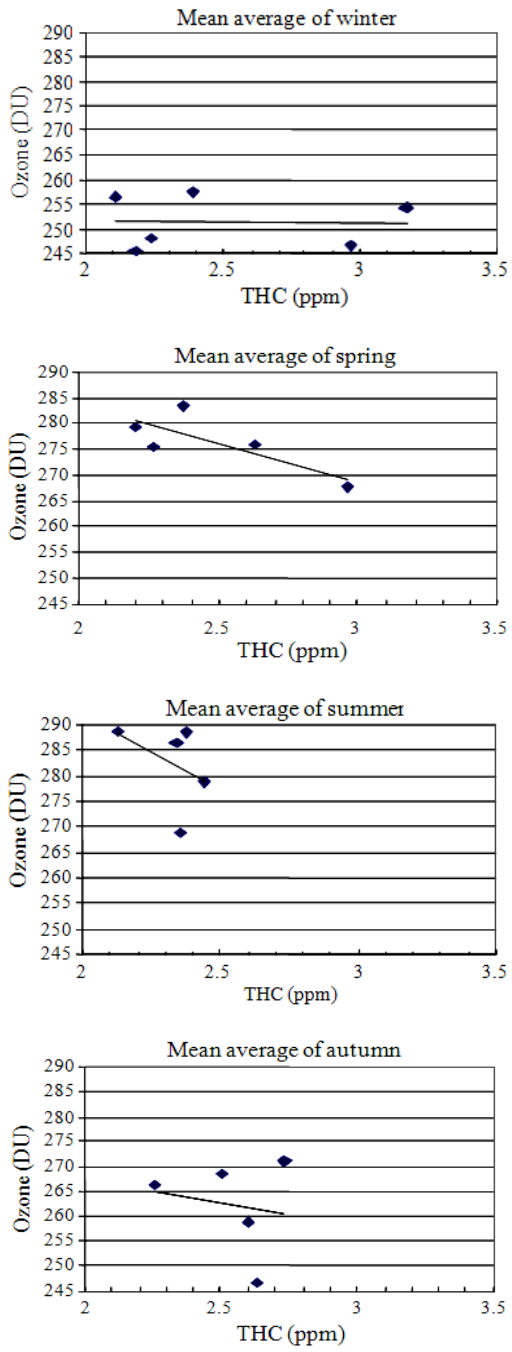

Fig. 4: The ozone thickness Vs THC per season for AlRiga station per years

After autumn there is slightly change in winter season. The higher Ozone thickness was Mar. and May. Moreover in summer instead of high concentration THC there were no effects of Ozone thickness in this season.

The dependency of ozone thickness on total nitrogen oxides: Emissions of NOx from biomass burning, land traffic, soils, ships, industry, air traffic, mineral dust (particles are often coated with nitrates, sulfates and organics), lightning, based on the strength of the convective mass flux and depth of convective clouds, stratospheric production.

The climate variability pattern is forced by the $\mathrm{El}$ Niño phenomenon, which increases lightning occurrence and lightning NOx emissions and leads to an inter-annual ozone variability of around $\pm 3 \%$ in the tropical upper

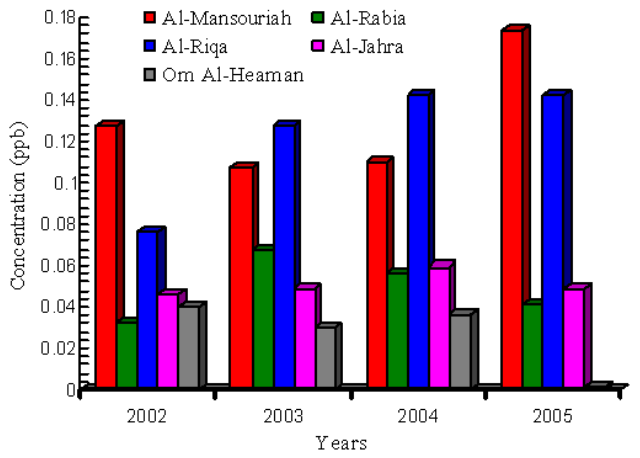

Fig. 5: Yearly mean concentration of NOx

Table 3: Hydrocarbon compound yearly concentration in $\mathrm{ppm}$ at different locations

\begin{tabular}{lllll}
\hline Area/year & 2002 & 2003 & 2004 & 2005 \\
\hline Al-Mansouria & 3.099 & 2.700 & 2.380 & 4.428 \\
Al-Rabia & 2.673 & 2.799 & 2.415 & 2.871 \\
Al-Riga & 2.483 & 2.169 & 2.244 & 2.463 \\
Al-Jahra & - & - & - & - \\
Om-Al-Heaman & - & - & - & - \\
\hline
\end{tabular}

Table 4: Yearly mean concentration of the total Nitrogen oxide ppb $\left(\mathrm{NO}_{\mathrm{x}}\right)$ by locations

\begin{tabular}{lllll}
\hline Area/years & 2002 & 2003 & 2004 & 2005 \\
\hline Al-Mansouriah & 0.128 & 0.107 & 0.110 & 0.174 \\
Al-Rabia & 0.033 & 0.067 & 0.056 & 0.041 \\
Al-Riqa & 0.076 & 0.127 & 0.142 & 0.143 \\
Al-Jahra & 0.046 & 0.048 & 0.059 & 0.049 \\
OmAl-Heaman & 0.039 & 0.030 & 0.036 & 0.001 \\
\hline
\end{tabular}

troposphere $^{[2]}$. Mineral dusts that have accumulated a coating of nitrate or aliphatic material will affect tropospheric ozone less than mineral dusts that have accumulated coatings of sulfite or olefins and the differences can potentially influence the partitioning of ozone in significant ways, changes in the composition of adsorbed material on the particles after reaction with ozone can also affect the physical characteristics of the particle, altering the hygroscopicity, absorptive properties, or ability to act as cloud condensation nuclei, the interaction of ozone with surface-bound olefins is shown to produce formaldehyde, which is an important compound in gas-phase tropospheric chemistry cycles, since formaldehyde is an important source of $\mathrm{HOx}^{[10]}$. In connection with $\mathrm{O}_{3}$ depletion events simultaneous decays of NMHCs and GEM have been observed, suggesting oxidation processes associated with reactions similar to those that destroy ozone $e^{[7,11-13]}$. To study the effects of yearly concentration of total Nitrogen oxide NOx (ppb) on ozone layer, from years 2002-2005 for five different stations. (Al-Mansouriah, Al-Rabia, Al-Riga, Al-Jahra and Om-Al-Heaman) were considered, in Kuwait. The results obtained from these stations are shown in Table 3 and 4.

Graphical representation of Table 4 is shown in Fig. 5. By analyzing the correlation between NOx 
during period (1999-2003) and how this correlation is linked with ozone layer thickness patterns.

This analysis makes it possible to examine hypotheses from a broader perspective and reveals significant results regarding the consistency of conclusions related to the mechanism depletion events.
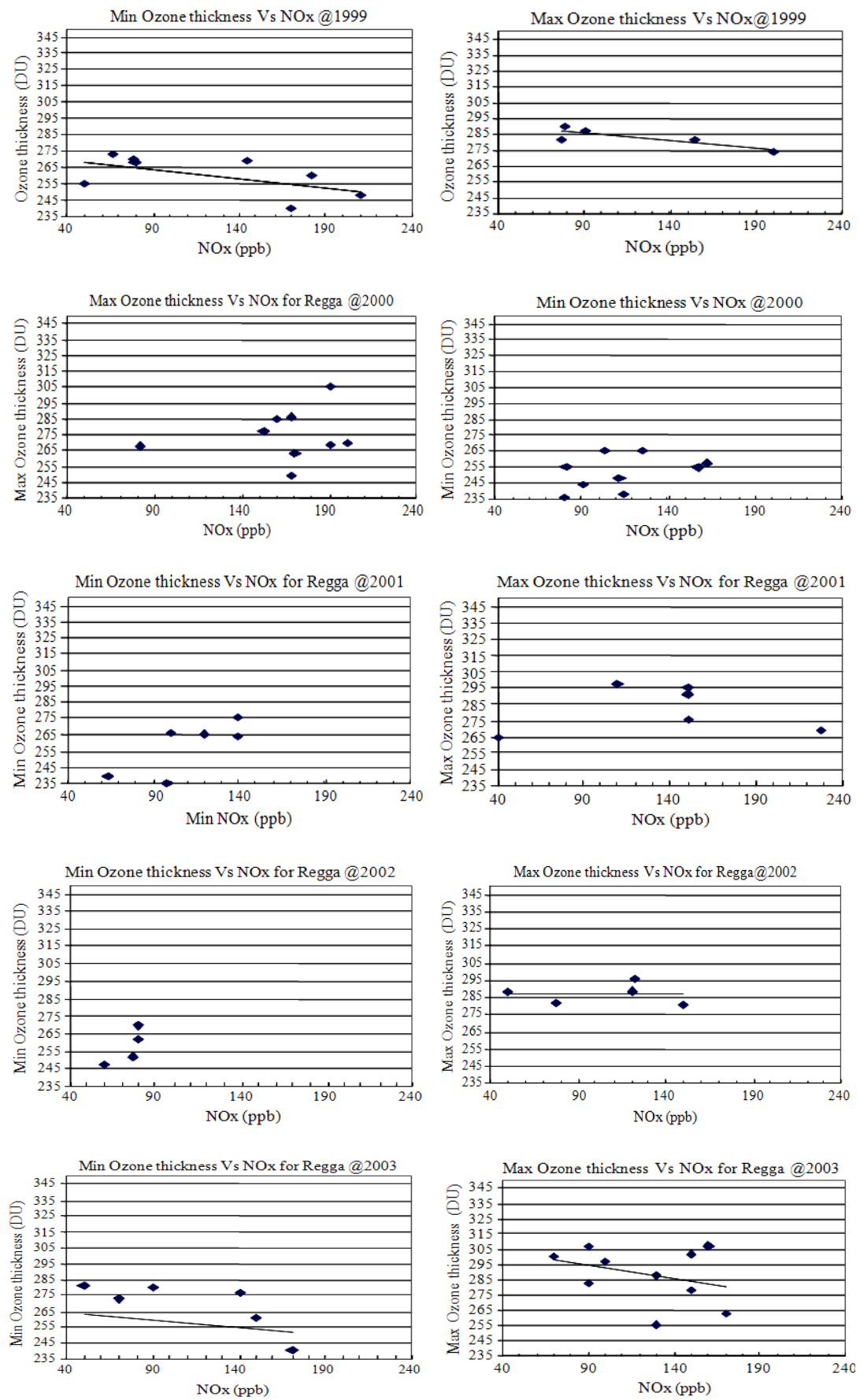

Fig. 6: Minimum and maximum yearly ozone thickness Vs NOx concentrations 
Am. J. Environ. Sci., 5 (3): 230-237, 2009
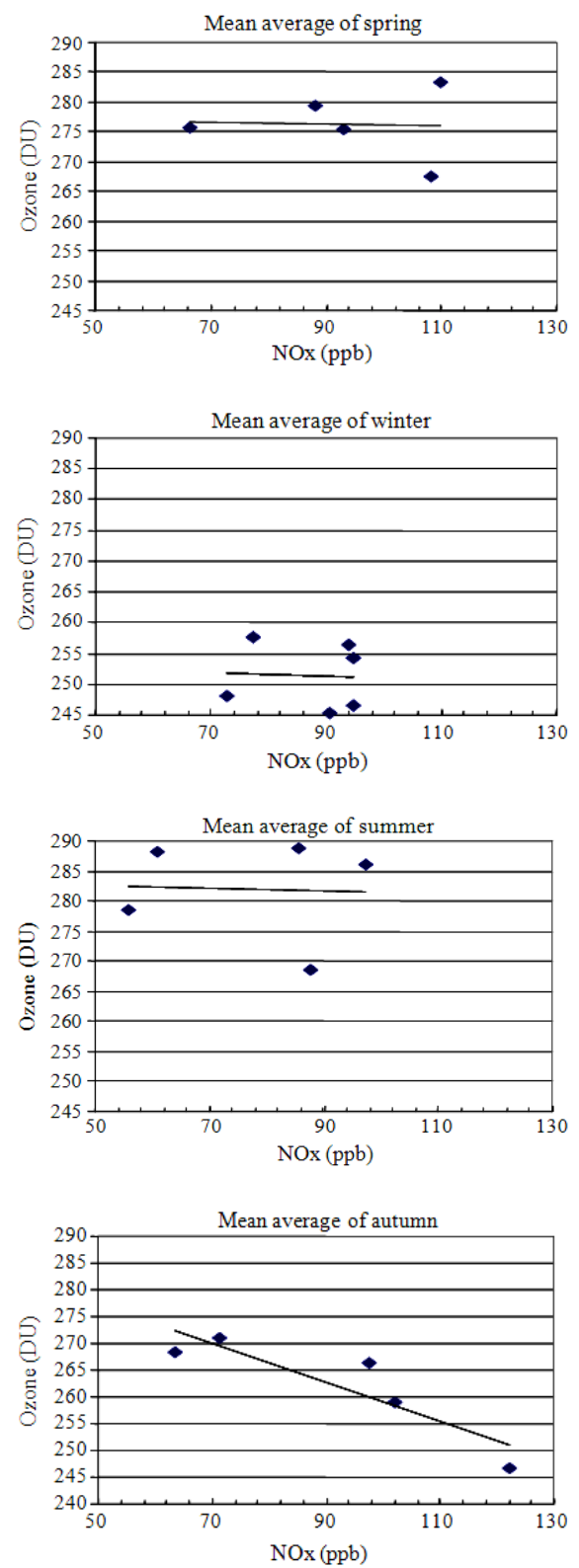

Fig. 7: Mean average ozone thickness Vs NOx per seasons

For year 1999 the minimum yearly ozone thickness is decreasing by the factor 0.114 for every $100 \mathrm{ppb}$ of NOx, concentration and for the same year for maximum yearly ozone thickness is decreasing with the factor 0.0955 for every $100 \mathrm{ppb}$ of NOx concentration.

So the change in ozone thickness is more with minimum values. For year 2000 and 2001 there were not any obvious trend and ozone layer thickness was almost unaltered during this time period. For the very next year in 2002 is ozone thickness is decreasing with slope of -0.738 for every $100 \mathrm{ppb}$ of NOx, concentration and another period in the same year, maximum yearly ozone thickness is decreasing with the slope of -0.0024 for every $100 \mathrm{ppb}$ of NOx concentration. So it is concluded that ozone layer thickness shows strong negative relation in the first period of year 2002. For the year 2003 the maximum ozone thickness is changing sharply with steep slope of -0.18 as compare to minimum ozone thickness, where slope was -0.094 .

Considering the influence of the seasons such as winter, spring, summer and autumn is in the corresponding months, January, March, May and August respectively.

As shown in Fig. 7, there are inverse proportional relation between Ozone thickness and NOx but the slope is changing sharply on autumn season then others. A strong positive correlation between autumn time $\mathrm{O}_{3}$ depletion events and NOx exists. After autumn there is slightly change in winter season. The higher Ozone thickness was noticed in spring and lower again in winter.

\section{CONCLUSION}

Ozone layer thickness in stratosphere has been measured for five years (1999-2004) reflect minimum thickness in the month of December and maximum in the month of June over Abu-Dhabi ozone monitoring station. The ozone thickness is also related to the ground level concentration of non-methane hydrocarbon and NOx independently. Ground level non-methane hydrocarbon and NOx concentrations can be used as an indicator for the health of the stratosphere ozone layer. A further study is required to forecast ozone layer thickness and the impact of ground level pollution.

\section{ACKNOWLEDGMENT}

The cooperation of the Embassy of United Arab Emirates and the Ministry of Presidential Affairs AbuDhabi National Centre of Meteorology and Seismology Abu-Dhabi Ozone Station is highly appreciated for providing the valuable data for completion of this project.

The information from Directorate General of Civil Aviation and Meteorological Department at Kuwait International Airport Administration, Ministry of Planning Statistic and Census Sector in Kuwait, Ministry of Finance General Administration of Customs in Kuwait are acknowledged. 


\section{REFERENCES}

1. Baldwin, M.P. and T.J. Dunkerton, 2005. The solar cycle and stratosphere-troposphere dynamical coupling. J. Atmosphere. Solar Terrest. Phys., 67: 71-82. DOI: $10.1016 /$ j.jastp.2004.07.018

2. Grewe, V., 2007. Impact of Clime Variability on troposphere ozone. Sci. Total Environ., 374: 167-181. DOI: 10.1016/j.scitotenv.2007.01.032

3. Brown, P., 2005. Ozone layer most fragile on record.

http://www.commondreams.org/headlines05/042701.htm

4. Chan, C.Y., Y .S. Li, J.H. Tang, Y.K. Leung, M.C. Wu, L.Y. Chan, C.C. Chang and S.C. Liu, 2007. An analysis on abnormally low ozone in the upper troposphere over subtropical East Asia in spring 2004. Atmospher. Environ., 41: 3556-3564. http://cat.inist.fr/?aModele $=$ afficheN\&cpsidt $=1872$ 5840

5. Tas, E., V. Matveev, J. Zingler, M. Luria and M. Peleg, 2003. Frequency and extent of ozone destruction episodes over the Dead Sea, Israel. Atmospher. Environ., 37: 4769-4780.

http://cat.inist.fr/?aModele $=$ afficheN\&cpsidt $=1516$ 688

6. Gabis, I. and O. Troshichev, 2006. Influence of solar UV irradiance on the quasi-biennial oscillation of zonal winds in the equatorial stratosphere. J. Atmospher. Solar Terrest. Phys., 68: 1987-1999. DOI: 10.1016/j.jastp.2006.05.017

7. Wikipedia, E., 2007. Air pollution, chapter 1, Ozone depletion. http://en.wikipedia.org/wiki/Airpollution
8. Usher, C.R., A.E. Michel, D. Stec and V.H. Grassian, 2003. Laboratory studies of ozone uptake on processed mineral dust. Atmospher. Environ., 37: 5337-5347.

DOI: $10.1016 /$ j.atmosenv.2003.09.014

9. Calvert, J., G. Lindberg and E. Steve, 2003. A modeling study of the mechanism of the halogenozone-mercury homogeneous reaction in troposphere during the polar spring. Atmospher. Environ., $\quad 37$ : 4467-4481. $\quad$ DOI: 10.1016/j.atmosenv.2003.07.001

10. Saraf, N. and G. Beig, 2003. Solar response in the vertical structure of ozone and temperature in the tropical stratosphere. J. Atmospher. Solar Terrest. Phys., 65: 1235-1243. DOI: 10.1016/j.jastp.2003.08.006

11. IPCC Special Reports, 2005. Safeguarding the ozone layer and the global climate system. http://www.cambridge.org/us/catalogue/catalogue.a sp?isbn $=9780521682060$

12. Enerotha, K., K. Holme, T. Berg, N. Schmidbauer and S. Solberg, 2007. Springtime depletion of tropospheric ozone, gaseous elemental mercury and non-methane hydrocarbons in the European Arctic and its relation to atmospheric transport. Atmosphere. Enviorn. 41: 8511-8526. http://cat.inist.fr/?aModele $=$ afficheN\&cpsidt $=1989$ 394

13. Powell, R.L., 2002. CFC phase-out: Have we met the challenge? J. Fluorine Chem., 114: 237-250. http://cat.inist.fr/?aModele $=$ afficheN\&cpsidt $=1367$ 5436 